\title{
Perancangan E-commerce Website Asy-Syifa CARE Menggunakan Framework PHP: CodeIgniter
}

\author{
Muhammad Farras Muttaqin ${ }^{1}$, Muhammad Fadzly Yusuf ${ }^{2}$, Mochammad Gatot Subroto ${ }^{3}$ \\ ${ }^{1}$ Universitas Trilogi \\ e-mail: farrasmuttaqin@gmail,com \\ ${ }^{2}$ Universitas Trilogi \\ e-mail: mfadzlyyusuf@trilogi.ac.id \\ ${ }^{3}$ Universitas Trilogi \\ e-mail: mgatotsubroto@trilogi.ac.id
}

\begin{abstract}
Problems regarding health complaints and community needs for herbal medicines always increasing in every year. The purpose of this research is to implement the Asy-Syifa CARE's e-commerce website which has a function as a media for promotion and selling of herbal medicines by online way. This research took a case on Asy-Syifa CARE startup, by collecting data through the secondary data sources. Data collection techniques carried out by the author is using literature studies on scientific journals related to e-commerce websites as a media for product promotion and sales. The results of this research is an e-commerce website using framework CodeIgniter version 3.1.9 that uses the MVC programming concept (Model-controller-view). Expectations from the results of this research is can helping Asy-Syifa CARE startup in improve the quality of their product branding in digital marketing, so they able to increase the revenue statistics and be able to compete with another e-commerce website competitors.
\end{abstract}

Keywords: e-commerce, website, CodeIgniter, MVC.

\section{PENDAHULUAN}

Berdasarkan data dari BPS yang dirilis tahun 2016, menyebutkan jumlah penduduk di Indonesia mencapai 261,1 juta jiwa (Anggraini, 2017). Sedangkan untuk hasil jumlah penduduk di DKI Jakarta sendiri adalah 10,17 juta jiwa pada tahun 2015 (BPS, 2015). Kemudian, berdasarkan data persentase penduduk perkotaan dan pendesaan yang mempunyai keluhan kesehatan di provinsi DKI Jakarta dari BPS yang dirilis tahun 2014, menyebutkan jumlah penduduk yang mempunyai keluhan kesehatan selama sebulan terakhir mencapai $64.25 \%$ dari jumlah seluruh penduduk DKI Jakarta (BPS, 2014). Setelah itu, berdasarkan data yang dirilis oleh SUSENAS tahun 2007 masyarakat yang menggunakan obat tradisional mencapai $28,69 \%$, yang pada tahun 2000 hanya 15,2\% (Supardi \& Susyanty, 2010). Untuk menjawab permasalahan mengenai tingginya tingkat keluhan kesehatan dan kebutuhan masyarakat terhadap obat-obatan herbal yang terus mengalami peningkatan dari setiap tahunnya, penulis berencana untuk melakukan perancangan e-commerce website Asy-Syifa Care.

Pada penelitian yang dilakukan oleh Prabowo, D. mengatakan bahwa e-commerce website dapat mempermudah kegiatan jualbeli sehingga customer tidak harus datang secara langsung ke toko penjual (Prabowo, 2015). Setelah itu, pada penelitian yang dilakukan oleh Assidqi, M., Prasetyo, Y. dan Adi, T. mengatakan bahwa aplikasi e-commerce tidak hanya mempermudah customer dalam melakukan pembelian produk, tetapi juga membantu dalam mendapat informasi produk sekaligus melakukan konfirmasi pembayaran (Assidqi, Prasetyo, \& Adi, 2015).

Asy-Syifa Care merupakan suatu ecommerce website yang menjual Obat-obatan Herbal, yang didapatkan melalui kerja sama dengan PT. HPA Indonesia. Tidak hanya sebagai sarana kegiatan jualbeli obat-obatan herbal, e-commerce ini juga memiliki konten blogs dan articles yang berfungsi sebagai media promosi sekaligus memberikan informasi tentang kesehatan kepada masyarakat. Website ini dikembangkan menggunakan framework CodeIgniter versi 3.1.9 dengan konsep Model-Control-View (MVC), yang dapat menghasilkan struktur pemrograman yang teratur dan dapat fokus terhadap fitur yang dibutuhkan oleh aplikasi web ini (Destiningrum \& Adrian, 2017).

\section{METODOLOGI PENELITIAN}

Dalam penelitian ini, terdapat beberapa tahapan penelitian. Tahapan penelitian yang dipaparkan berguna untuk memberikan gambaran tentang keseluruhan proses pelaksanaan penelitian 
yang dilakukan dari awal hingga akhir. Tahapan tersebut dapat dilihat pada gambar 1 dibawah ini :

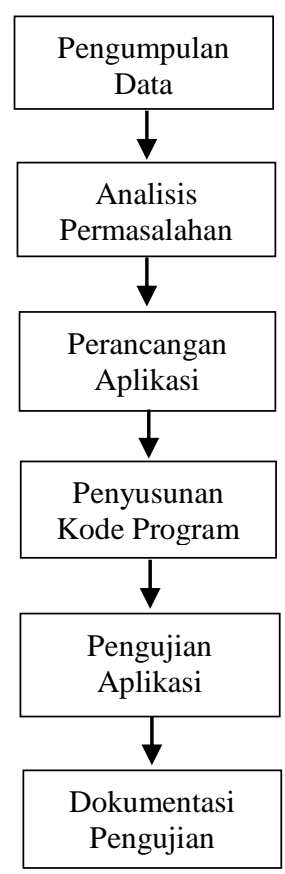

Gambar 1. Tahapan Penelitian

\subsection{Pengumpulan Data}

Data yang dikumpulkan, merupakan hasil dari suatu lembaga yang ditunjukkan oleh Badan Pusat Statistik (BPS) dan SUSENAS. Sehingga dapat disimpulkan bahwa, tidak sedikit masyarakat yang masih merasakan keluhan terhadap kesehatan serta kurangnya informasi terkait keberadaan obat herbal yang layak. Sehingga, hal ini menjadi sebuah permasalahan dalam kebutuhan bermasyarakat.

\subsection{Analisis Permasalahan}

Dari hasil analisis permasalahan terhadap hasil pengumpulan data yang diperoleh sebelumnya, penulis berencana untuk membuat sebuah $e$ commerce website dalam bidang kesehatan dengan fitur layanan transaksi dalam penyediaan obat-obatan herbal yang berkualitas. Tujuannya adalah memudahkkan masyarakat untuk memperoleh informasi tentang kesehatan, serta mendapatkan obatobatan herbal yang berkualitas secara cepat dan mudah.

\subsection{Perancangan Aplikasi Web}

Tahap awal yang penulis lakukan dalam merancang sebuah aplikasi web, adalah dengan membuat gambaran atau prototype dari aplikasi yang akan dibangun, baik dari arsitektur tampilan hingga fitur-fitur yang akan digunakan untuk memudahkan dalam bertransaksi dengan customer.

2.4 Penyusunan Kode Program

Hasil perancangan yang sudah tergambarkan, penulis mulai menyusun kode program menggunakan framework CodeIgniter versi 3.1.9 dengan konsep Model-Control-View (MVC) yang membantu dalam penyusunan kode program menjadi lebih rapi dan terstruktur (Heriyanto, Kurniawan, \& Taufik, 2017). Kemudian, penyusunan kode program ini dilakukan secara berkala, sehingga dibutuhkan ketelitian dalam membuatnya agar aplikasi yang digunakan terasa mudah dan nyaman bagi costumer.

\subsection{Pengujian Aplikasi Web}

Setelah menyusun seluruh kode program yang akan digunakan dalam membangun sebuah aplikasi web, penulis melakukan pengujian terhadap aplikasi web menggunakan black box. Tujuannya agar mengetahui bagian-bagian dari fitur manakah yang masih terdapat error atau crash.

\subsection{Dokumentasi Pengujian}

Jika pada tahap pengujian aplikasi tidak terdapat sesuatu yang menyebabkan error maka aplikasi siap untuk dipasarkan. Penulis akan melakukan dokumentasi pengujian sebagai tanda aplikasi sudah masuk kategori layak pakai.

\section{HASIL DAN PEMBAHASAN}

Terdapat 4 tahapan yang akan dijelaskan pada hasil dan pembahasan. Yaitu, rancangan desain aplikasi web menggunakan use case diagram, rancangan model data, rancangan class diagram, implementasi aplikasi web dan uji coba aplikasi web menggunakan black box.

\subsection{Rancangan Use Case Diagram}

Use case diagram digunakan untuk memodelkan kebutuhan fungsional dari aplikasi web yang akan dibuat (Hendini, 2016), dalam hal ini use case diagram pembelian produk di website Asy-Syifa CARE dapat dilihat pada Gambar 2 dibawah ini.

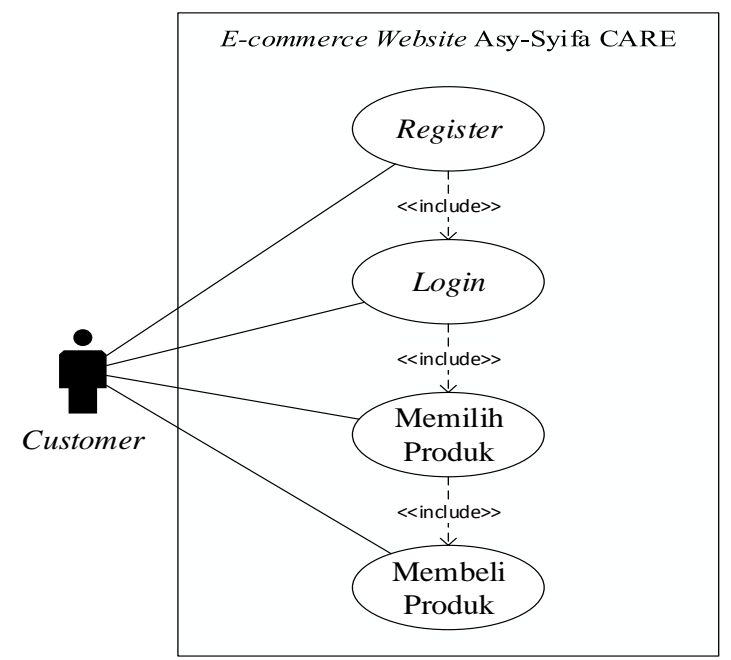

Gambar 2. Use Case Diagram Pembelian Produk 
Gambar 2 merupakan use case diagram yang menjelaskan behavior atau prilaku customer dalam membeli produk di e-commerce website AsySyifa CARE. Customer wajib memiliki akun AsySyifa CARE sebelum melakukan pembelian produk, oleh karena itu customer dapat daftar untuk mendapatkan akun Asy-Syifa CARE. Relasi antar use case atau Dependency pada Gambar 2 diatas adalah include, karena use case tersebut memiliki keberadaan yang saling membutuhkan satu sama lain.

Setelah customer membeli suatu produk, maka admin website akan melakukan konfirmasi pembayaran produk customer. Adapun use case diagram konfirmasi pembayaran yang dilakukan oleh admin website dapat dilihat pada Gambar 3 dibawah ini.

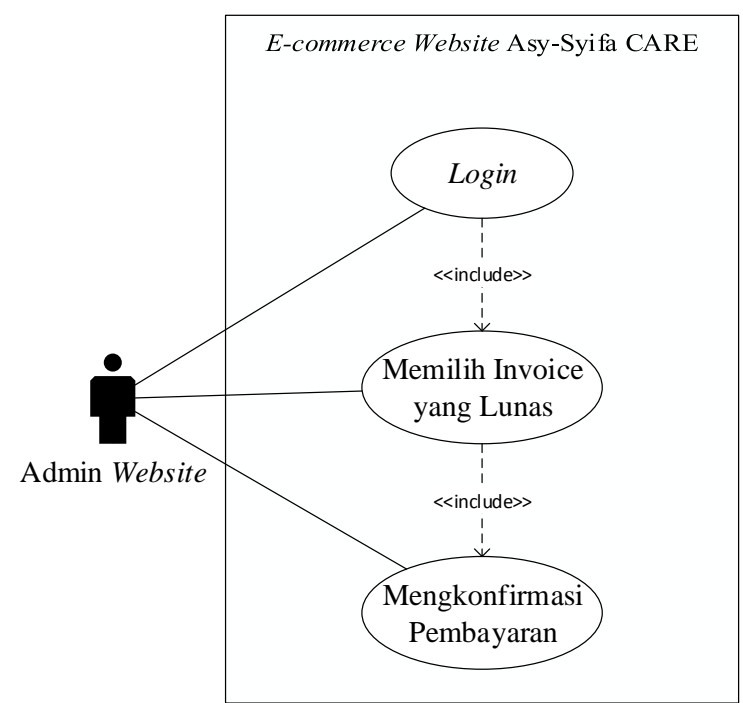

Gambar 3. Use Case Diagram Konfirmasi Pembayaran Produk

Gambar 3 merupakan use case diagram prilaku website admin dalam melakukan konfirmasi pembayaran produk. Website admin wajib login terlebih dahulu ke dalam admin dashboard Asy-Syifa CARE untuk mengkonfirmasi pembayaran produk customer. Sama halnya dengan use case diagram pembelian produk, relasi antar use case atau Dependency pada Gambar 3 diatas adalah include. Karena use case tersebut memiliki keberadaan yang saling membutuhkan satu sama lain.

\subsection{Rancangan Model Data}

Pada perancangan model data digambarkan dengan desain integrasi data menggunakan skema database dan struktur setiap tabel yang ada di dalam skema database. Pada Gambar 4 di bawah ini menjelaskan desain integrasi data e-commerce website Asy-Syifa CARE menggunakan skema database.

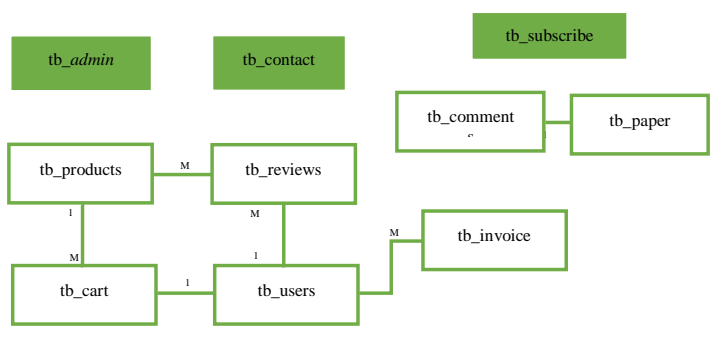

Gambar 4. Skema Database

Berdasarkan skema database pada Gambar 4 diatas, terdapat 10 tabel pada e-commerce website Asy-Syifa CARE. Adapun tabel-tabel tersebut adalah sebagai berikut :

a) Tabel tb_admin

Tabel 1.tb_admin

\begin{tabular}{cccccc}
\hline No & Field & Type & Length & Extra & Key \\
\hline 1 & Id_admin & Int & 10 & $\begin{array}{c}\text { Auto } \\
\text { increment }\end{array}$ & $\begin{array}{c}\text { Primar } \\
\text { y key }\end{array}$ \\
\hline 2 & $\begin{array}{c}\text { Nama_le } \\
\text { ngkap }\end{array}$ & Varchar & 100 & & \\
\hline 3 & Username & Varchar & 100 & & \\
\hline 4 & Pass & Varchar & 100 & & \\
\hline
\end{tabular}

b) Tabel tb_cart

Tabel 2.tb_cart

\begin{tabular}{cccccc}
\hline No & Field & Type & Length & Extra & Key \\
\hline 1 & Id_cart & Int & 10 & $\begin{array}{c}\text { Auto } \\
\text { increment }\end{array}$ & $\begin{array}{c}\text { Primar } \\
\text { y key }\end{array}$ \\
\hline 2 & Id_user & Int & 10 & $\begin{array}{c}\text { Foreig } \\
\text { n Key }\end{array}$ \\
\hline 3 & $\begin{array}{c}\text { Id_produ } \\
\text { ct }\end{array}$ & int & 10 & $\begin{array}{c}\text { Foreig } \\
\text { n Key }\end{array}$ \\
\hline 4 & $\begin{array}{c}\text { Nomor_i } \\
\text { nvoice }\end{array}$ & Varchar & 100 & \\
\hline 5 & Quantity & Int & 10 & \\
\hline 6 & $\begin{array}{c}\text { Nama_pr } \\
\text { oduct }\end{array}$ & Varchar & 200 & \\
\hline 7 & $\begin{array}{c}\text { Harga_pr } \\
\text { oduct }\end{array}$ & Int & 20 & \\
\hline 8 & $\begin{array}{c}\text { Gambar_ } \\
\text { product }\end{array}$ & Varchar & 150 & \\
\hline 9 & Email & Varchar & 150 & \\
\hline
\end{tabular}

c) Tabel tb_comment

Tabel 3. tb_comment

\begin{tabular}{cccccc}
\hline No & Field & Type & Length & Extra & Key \\
\hline 1 & $\begin{array}{c}\text { Id_comm } \\
\text { ent }\end{array}$ & Int & 10 & $\begin{array}{c}\text { Auto } \\
\text { increment }\end{array}$ & $\begin{array}{c}\text { Primar } \\
\text { y key }\end{array}$ \\
\hline 2 & Id_paper & Int & 10 & & $\begin{array}{c}\text { Foreig } \\
\text { n Key }\end{array}$ \\
\hline 3 & Nama & Varchar & 100 & & \\
\hline 4 & Komen & Text & & & \\
\hline 5 & $\begin{array}{c}\text { Tanggal_ } \\
\text { komen }\end{array}$ & Varchar & 50 & & \\
\hline
\end{tabular}


d) Tabel tb_contact

Tabel 4. tb_contact

\begin{tabular}{cccccc}
\hline No & Field & Type & Length & Extra & Key \\
\hline 1 & $\begin{array}{c}\text { Id_contac } \\
\mathrm{t}\end{array}$ & Int & 10 & $\begin{array}{c}\text { Auto } \\
\text { increment }\end{array}$ & $\begin{array}{c}\text { Primar } \\
\text { y key }\end{array}$ \\
\hline 2 & Nama & Varchar & 100 & & \\
\hline 3 & Email & Varchar & 100 & & \\
\hline 4 & Subject & Varchar & 200 & & \\
\hline 5 & Message & Text & & & \\
\hline
\end{tabular}

e) Tabel tb_invoice

Tabel 5.tb_invoice

\begin{tabular}{|c|c|c|c|c|c|}
\hline No & Field & Type & Length & Extra & Key \\
\hline 1 & $\begin{array}{c}\text { Id_invoic } \\
\mathrm{e}\end{array}$ & Int & 10 & $\begin{array}{c}\text { Auto } \\
\text { increment }\end{array}$ & $\begin{array}{c}\text { Primar } \\
\text { y key }\end{array}$ \\
\hline 2 & $\begin{array}{c}\text { Nomor_i } \\
\text { nvoice }\end{array}$ & Int & 20 & & \\
\hline 3 & Id_user & Int & 10 & & $\begin{array}{l}\text { Foreig } \\
n \text { Key }\end{array}$ \\
\hline 4 & $\begin{array}{c}\text { Biaya_tot } \\
\text { al }\end{array}$ & Int & 20 & & \\
\hline 5 & $\begin{array}{l}\text { Biaya_pe } \\
\text { ngiriman }\end{array}$ & Int & 20 & & \\
\hline 6 & $\begin{array}{c}\text { Status_pe } \\
\text { nerimaan } \\
\text { _barang }\end{array}$ & Varchar & 50 & & \\
\hline 7 & $\begin{array}{l}\text { Status_pe } \\
\text { mbayaran }\end{array}$ & Varchar & 50 & & \\
\hline 8 & $\begin{array}{l}\text { Alamat_p } \\
\text { engiriman }\end{array}$ & Text & & & \\
\hline 9 & Kota & Varchar & 50 & & \\
\hline 10 & Provinsi & Varchar & 150 & & \\
\hline 11 & Kode_pos & Varchar & 50 & & \\
\hline 12 & $\begin{array}{c}\text { Bukti_tra } \\
\text { nsaksi }\end{array}$ & Varchar & 150 & & \\
\hline 13 & Catatan & Text & & & \\
\hline 14 & $\begin{array}{c}\text { Tanggal_i } \\
\text { nvoice }\end{array}$ & Varchar & 200 & & \\
\hline
\end{tabular}

f) Tabel tb_paper

Tabel 6. tb_paper

\begin{tabular}{cccccc}
\hline No & Field & Type & Length & Extra & Key \\
\hline 1 & Id_paper & Int & 10 & $\begin{array}{c}\text { Auto } \\
\text { increment }\end{array}$ & $\begin{array}{c}\text { Primar } \\
\text { y key }\end{array}$ \\
\hline 2 & Jenis & Varchar & 50 & & \\
\hline 3 & Judul & Varchar & 200 & & \\
\hline 4 & $\begin{array}{c}\text { Tanggal_ } \\
\text { publish }\end{array}$ & Varchar & 50 & & \\
\hline 5 & $\begin{array}{c}\text { Nama_pe } \\
\text { mbuat }\end{array}$ & Varchar & 50 & \\
\hline 6 & Isi & Text & & \\
\hline 7 & Tags & Varchar & 200 & \\
\hline 8 & $\begin{array}{c}\text { Kalimat_ } \\
\text { pendek }\end{array}$ & Text & & \\
\hline 9 & $\begin{array}{c}\text { Thumbna } \\
\text { il }\end{array}$ & Varchar & 50 & \\
\hline
\end{tabular}

g) Tabel tb_products

Tabel 7.tb_products

\begin{tabular}{cccccc}
\hline No & Field & Type & Length & Extra & Key \\
\hline 1 & Id_produ & Int & 10 & $\begin{array}{c}\text { Auto } \\
\text { increment }\end{array}$ & $\begin{array}{c}\text { Primar } \\
\text { y key }\end{array}$ \\
\hline 2 & Nama_pr & Varchar & 75 & & \\
\hline
\end{tabular}

\begin{tabular}{|c|c|c|c|}
\hline & oduct & & \\
\hline 3 & $\begin{array}{c}\text { Harga_pr } \\
\text { oduct }\end{array}$ & Int & 15 \\
\hline 4 & $\begin{array}{c}\text { Jenis_pro } \\
\text { duct }\end{array}$ & Varchar & 50 \\
\hline 5 & $\begin{array}{l}\text { Deskripsi } \\
\text { _product }\end{array}$ & Text & \\
\hline 6 & $\begin{array}{l}\text { Addinfo_ } \\
\text { product }\end{array}$ & Text & \\
\hline 7 & Stock & Int & 15 \\
\hline 8 & $\begin{array}{c}\text { Gambar_ } \\
\text { product }\end{array}$ & Varchar & 50 \\
\hline 9 & $\begin{array}{c}\text { Deskripsi } \\
\text { _singkat__ } \\
\text { product }\end{array}$ & Text & \\
\hline
\end{tabular}

h) Tabel tb_reviews

Tabel 8. tb_reviews

\begin{tabular}{cccccc}
\hline No & Field & Type & Length & Extra & Key \\
\hline 1 & $\begin{array}{c}\text { Id_review } \\
\text { s }\end{array}$ & Int & 10 & $\begin{array}{c}\text { Auto } \\
\text { increment }\end{array}$ & $\begin{array}{c}\text { Primar } \\
\text { y key }\end{array}$ \\
\hline 2 & Id_user & Int & 50 & & $\begin{array}{c}\text { Foreig } \\
n \text { Key }\end{array}$ \\
\hline 3 & $\begin{array}{c}\text { Id_produ } \\
\text { ct }\end{array}$ & Int & 50 & $\begin{array}{c}\text { Foreig } \\
n \text { Key }\end{array}$ \\
\hline 4 & Rating & Varchar & 50 & & \\
\hline 5 & Reason & Text & & & \\
\hline 6 & Komen & Varchar & 200 & & \\
\hline 7 & $\begin{array}{c}\text { Tanggal_ } \\
\text { reviews }\end{array}$ & Varchar & & & \\
\hline 8 & $\begin{array}{c}\text { Nama_de } \\
\text { pan_revie } \\
\text { wers }\end{array}$ & Varchar & 50 & & \\
& & & & \\
\hline
\end{tabular}

i) Tabel tb_subscribe

Tabel 9. tb_suscribe

\begin{tabular}{cccccc}
\hline No & Field & Type & Length & Extra & Key \\
\hline 1 & $\begin{array}{c}\text { Id_subscr } \\
\text { ibe }\end{array}$ & Int & 10 & $\begin{array}{c}\text { Auto } \\
\text { increment }\end{array}$ & $\begin{array}{c}\text { Primar } \\
\text { y key }\end{array}$ \\
\hline 2 & Email & Varchar & 100 & & \\
\hline
\end{tabular}

j) Tabel tb_users

Tabel 10. tb users

\begin{tabular}{cccccc}
\hline No & Field & Type & Length & Extra & Key \\
\hline 1 & Id_user & Int & 10 & $\begin{array}{c}\text { Auto } \\
\text { increment }\end{array}$ & $\begin{array}{c}\text { Primar } \\
\text { y key }\end{array}$ \\
\hline 2 & $\begin{array}{c}\text { Nama_le } \\
\text { ngkap }\end{array}$ & Varchar & 40 & & \\
\hline 3 & Email & Text & & & \\
\hline 4 & Pass & Varchar & 32 & & \\
\hline 5 & Hashh & Varchar & 40 & & \\
\hline 6 & Active & Int & 1 & & \\
\hline 7 & $\begin{array}{c}\text { Awal_joi } \\
\text { n }\end{array}$ & Varchar & 50 & & \\
\hline 8 & $\begin{array}{c}\text { Nomor_h } \\
\text { p }\end{array}$ & Varchar & 50 & & \\
\hline
\end{tabular}

\subsection{Rancangan Class Diagram}

Class diagram merupakan penjelasan detail hubungan antar kelas yang di sajikan dalam model desain dari suatu sistem. Tidak hanya itu, class diagram juga menunjukkan atribut, operasi dan constraint yang terdapat pada sebuah kelas (Isa \& 
Hartawan, 2017). Berikut adalah struktur class diagram yang terdapat pada bagian controller.

\begin{tabular}{|c|c|}
\hline Controller & \\
\hline Login_controller & \multirow{5}{*}{ 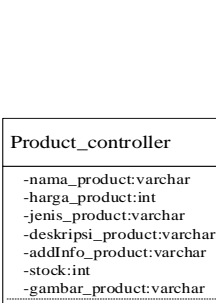 } \\
\hline $\begin{array}{l}\text {-email:varchar } \\
\text {-password:varchar } \\
\text {-notelp:varchar } \\
\text {-nama_lengkap:varchar }\end{array}$ & \\
\hline $\begin{array}{l}\text {-date:varchar } \\
\text {-active:int }\end{array}$ & \\
\hline $\begin{array}{l}+ \text { index }( \\
+\operatorname{loginAction}( \\
+ \text { forgotAction() } \\
+ \text { +changePassword() } \\
\text { +register }(\end{array}$ & \\
\hline & \\
\hline Checkout_controller & \multirow{4}{*}{ 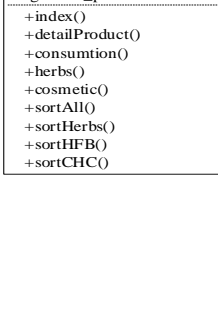 } \\
\hline $\begin{array}{l}\text {-biaya_total:int } \\
\text {-biaya_pengiriman:int } \\
\text {-status_penerimaan_bbarang:varchar } \\
\text {-status_pembayaran:varchar } \\
\text {-alamat__pengiriman:varchar } \\
\text {-kota:varchar } \\
\text {-provinsi:varchar }\end{array}$ & \\
\hline $\begin{array}{l}\text {-kode_pos:varchar } \\
\text {-bukti_transaksi:varchar }\end{array}$ & \\
\hline $\begin{array}{l}\text { +index }() \\
\text { +pembayaran } O \\
\text { +order } 0 \\
\text { +detial } \\
\text { +inputCheckout } O \\
\end{array}$ & \\
\hline
\end{tabular}

\section{Gambar 4. Controller Class Diagram}

Gambar 4 diatas merupakan struktur class diagram yang terdapat pada bagian controller. Adapun struktur class diagram yang terdapat pada bagian model di jabarkan pada Gambar 5 di bawah ini.

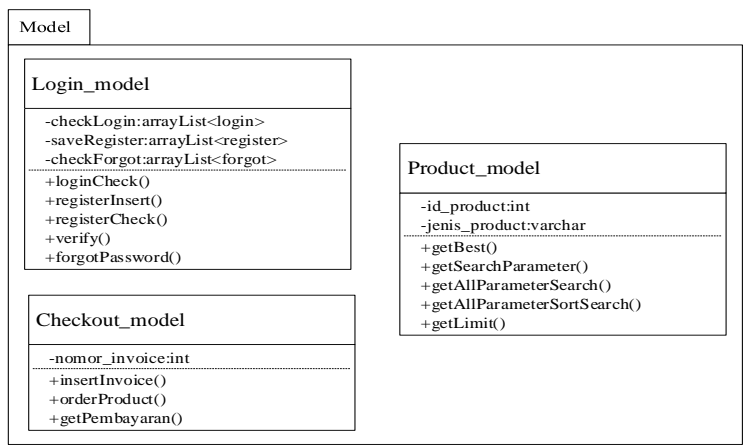

Gambar 5. Model Class Diagram

3.3 Implementasi Aplikasi Web

Pada tahap implementasi, e-commerce website Asy-Syifa CARE sudah dijalankan secara online. Domain dari Asy-Syifa CARE adalah www.asysyifacare.com. Aplikasi web Asy-Syifa CARE terbagi atas dua, yaitu dari sisi customer dan dari sisi admin. Berikut ini tampilan user interface dari sisi customer dan admin sebagai berikut.

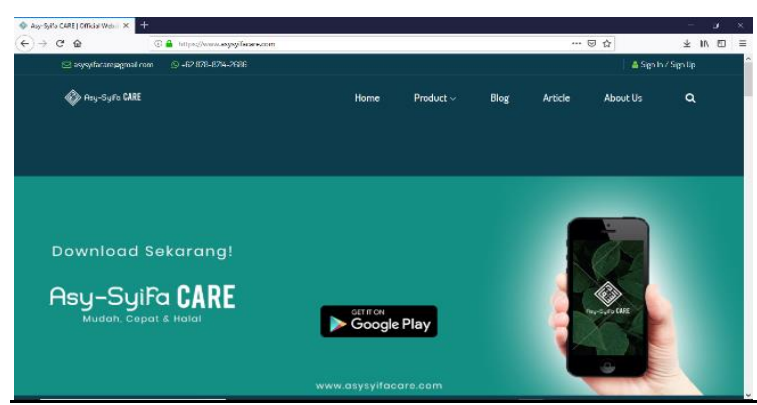

Gambar 6. Halaman Homepage

Gambar 6 menjelaskan tampilan antarmuka untuk halaman homepage. Halaman ini menampilkan informasi tentang top product dan artikel yang ada di website, serta beberapa testimoni dari customer yang terdapat untuk website Asy-Syifa CARE.

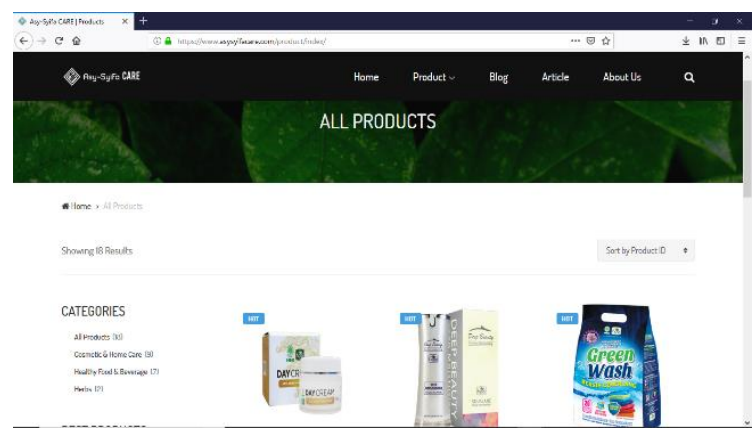

Gambar 7. Halaman All Products

Gambar 7 adalah halaman all products. Pada halaman ini terdapat informasi berupa semua product yang dijual. Customer dapat melakukan pemesanan product herbal berdasarkan fungsi kegunaannya dari beberapa kategori yang tersedia, yaitu kategori Cosmetic \& Home Care, Healthy Food \& Beverage, dan Herbs.

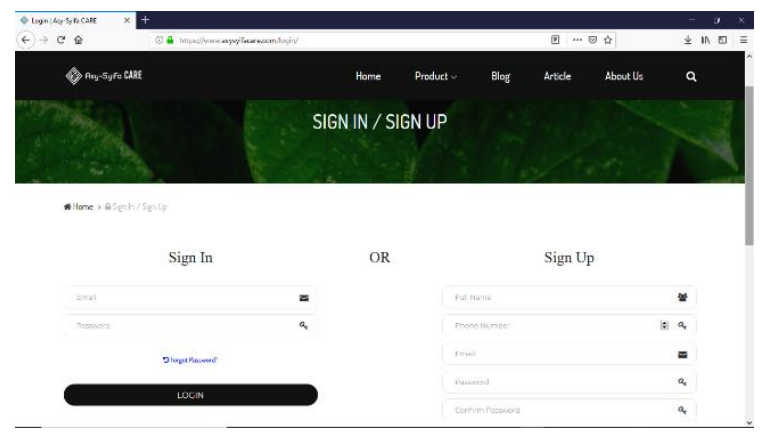

Gambar 8. Halaman Sign in / Sign up

Gambar 8 adalah halaman sign in/sign up. Pada halaman ini user dapat sign up atau mendaftar untuk menjadi customer Asy-Syifa CARE. Namun jika user sudah terdaftar sebagai customer Asy-Syifa CARE, maka user dapat langsung sign in. 


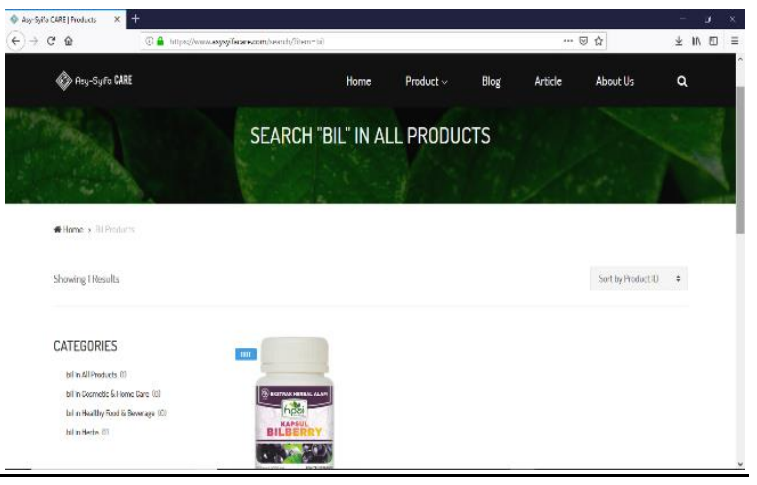

Gambar 9. Halaman Search

Gambar 9 adalah halaman search atau pencarian produk. Halaman ini akan menampilkan hasil pencarian berdasarkan kriteria pencarian yang diinputkan oleh customer.

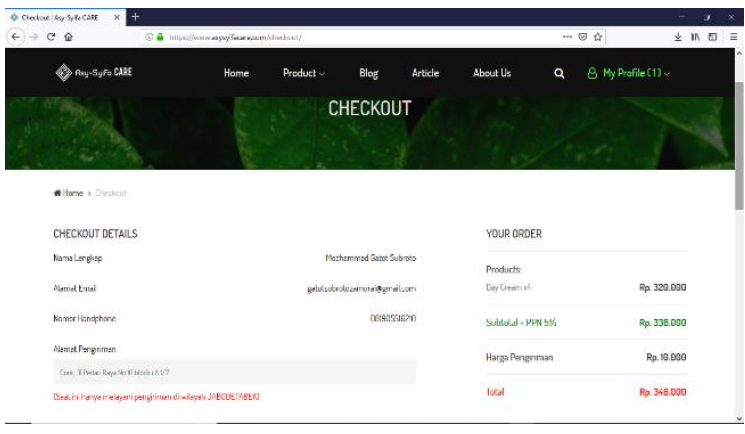

Gambar 10. Halaman Checkout

Gambar 10 adalah tampilan dari halaman checkout. Halaman ini digunakan sebagai konfirmasi pembelian product yang dilakukan oleh customer. Di halaman ini terdapat informasi seperti data profile customer dan form pengisian alamat pengiriman, serta informasi harga barang yang telah di pesan.

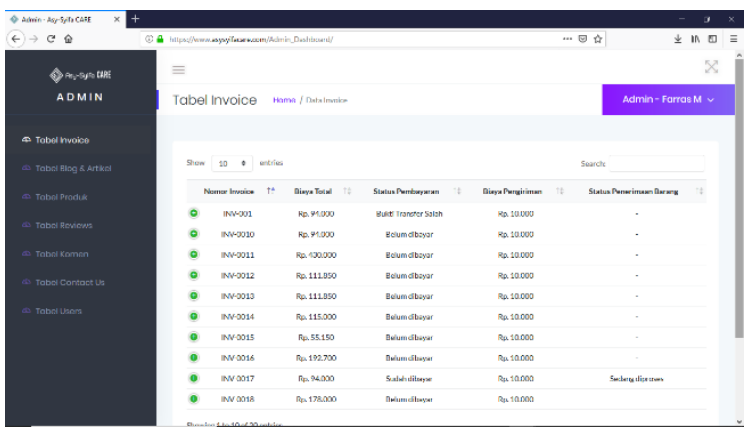

Gambar 11. Halaman Kelola Invoice

Gambar 11 merupakan tampilan dari halaman kelola invoice. Pada halaman ini admin dapat melihat daftar status pemesanan dari customer, dapat melakukan pengecekan terhadap bukti transaksi dan dapat mengkonfirmasi pemesanan customer jika bukti transaksi benar.

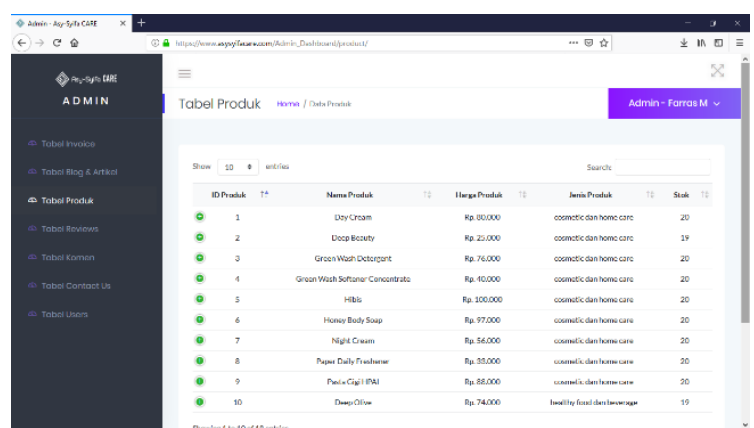

Gambar 12. Halaman Kelola Produk

Gambar 12 merupakan tampilan dari halaman kelola produk. Pada halaman ini admin dapat mengelola semua informasi dari produk yang ada di dalam database, seperti menambahkan, mengedit dan menghapus terhadap produk yang dimiliki.

\subsection{Uji Coba Aplikasi Web}

Pada tahap ini dilakukan pengujian aplikasi web menggunakan black box berdasarkan hasil dari implementasi aplikasi web. Tujuan dilakukan pengujian aplikasi menggunakan black box adalah untuk menguji kelayakan aplikasi dan mengecek kembali aplikasi agar terhindar dari bug ataupun error (Suandi, Khasanah, \& Retnoningsih, 2017). Karena aplikasi web ini terbagi menjadi 2 (dua) yaitu dari sisi Customer dan dari sisi Admin, maka pengujian akan dimulai dari sisi Customer. Berikut adalah Tabel 11 pengujian pembelian produk :

Tabel 11. Pengujian Pembelian Produk

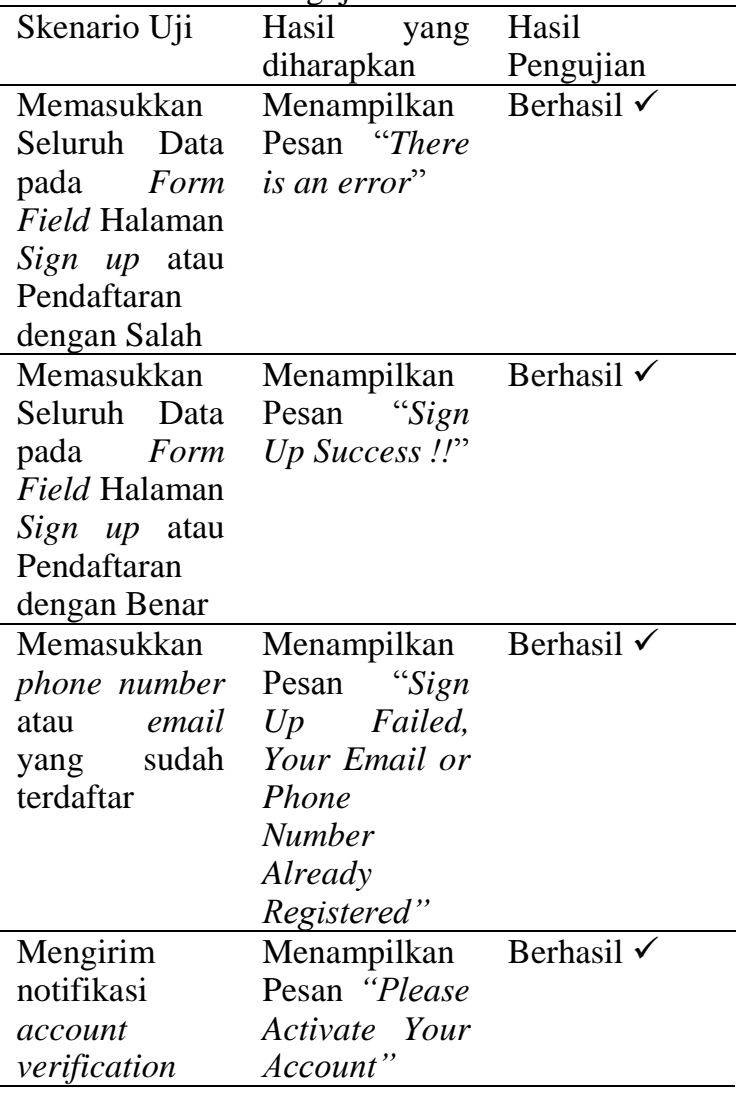




\begin{tabular}{|c|c|c|}
\hline $\begin{array}{l}\text { pada email } \\
\text { pendaftar }\end{array}$ & & \\
\hline $\begin{array}{l}\text { Memasukkan } \\
\text { email dan } \\
\text { password pada } \\
\text { Form Login } \\
\text { dengan Salah }\end{array}$ & $\begin{array}{l}\text { Menampilkan } \\
\text { Pesan "Login } \\
\text { Failed Your } \\
\text { Email } \\
\text { Password } \\
\text { Wrong" }\end{array}$ & Berhasil $\checkmark$ \\
\hline $\begin{array}{l}\text { Memasukkan } \\
\text { email dan } \\
\text { password pada } \\
\text { Form Login } \\
\text { dengan Benar }\end{array}$ & $\begin{array}{l}\text { Menampilkan } \\
\text { Halaman } \\
\text { Home }\end{array}$ & Berhasil $\checkmark$ \\
\hline $\begin{array}{l}\text { Mencari nama } \\
\text { produk yang } \\
\text { terdapat pada } \\
\text { website Asy- } \\
\text { Syifa CARE. }\end{array}$ & $\begin{array}{l}\text { Menampilkan } \\
\text { seluruh } \\
\text { produk yang } \\
\text { sesuai dengan } \\
\text { pencarian }\end{array}$ & Berhasil $\checkmark$ \\
\hline $\begin{array}{l}\text { Mencari nama } \\
\text { produk yang } \\
\text { tidak terdapat } \\
\text { pada website } \\
\text { Asy-Syifa } \\
\text { CARE. }\end{array}$ & $\begin{array}{l}\text { Tidak } \\
\text { menampilkan } \\
\text { produk } \\
\text { apapun. }\end{array}$ & Berhasil $\checkmark$ \\
\hline $\begin{array}{l}\text { Menekan } \\
\text { tombol } \\
\text { checkout }\end{array}$ & $\begin{array}{l}\text { Menampilkan } \\
\text { seluruh } \\
\text { produk yang } \\
\text { telah } \\
\text { dimasukkan } \\
\text { ke dalam cart } \\
\text { berserta } \\
\text { quantity, } \\
\text { harga satuan } \\
\text { dan harga } \\
\text { totalnya }\end{array}$ & Berhasil $\checkmark$ \\
\hline $\begin{array}{l}\text { Memasukkan } \\
\text { alamat } \\
\text { pengiriman } \\
\text { tidak benar }\end{array}$ & $\begin{array}{l}\text { Menampilkan } \\
\text { Pesan "There } \\
\text { is an error" }\end{array}$ & Berhasil $\checkmark$ \\
\hline $\begin{array}{l}\text { Memasukkan } \\
\text { alamat } \\
\text { pengiriman } \\
\text { dengan benar }\end{array}$ & $\begin{array}{l}\text { Menampilkan } \\
\text { Halaman } \\
\text { Upload Bukti } \\
\text { Pembayaran }\end{array}$ & Berhasil $\checkmark$ \\
\hline $\begin{array}{l}\text { Meng-upload } \\
\text { gambar bukti } \\
\text { pembayaran } \\
\text { dengan tipe } \\
\text { file png, jpg } \\
\text { atau jpeg }\end{array}$ & $\begin{array}{l}\text { Menyimpan } \\
\text { gambar bukti } \\
\text { pembayaran } \\
\text { ke dalam } \\
\text { folder "bukti } \\
\text { pembayaran" }\end{array}$ & Berhasil $\checkmark$ \\
\hline $\begin{array}{l}\text { Meng-upload } \\
\text { gambar bukti } \\
\text { pembayaran } \\
\text { dengan tipe } \\
\text { file selain png, } \\
\text { jpg atau jpeg }\end{array}$ & $\begin{array}{l}\text { Menampilkan } \\
\text { Pesan } \\
\text { "Uploaded } \\
\text { file is not a } \\
\text { valid image" }\end{array}$ & Berhasil $\checkmark$ \\
\hline
\end{tabular}

Berdasarkan hasil pengujian pembelian produk pada Tabel 11 diatas, menunjukkan bahwa seluruh fungsi yang diperlukan dalam melakukan pembelian suatu produk di e-commerce website AsySyifa CARE berjalan sesuai dengan hasil yang diharapkan. Setelah itu dilanjutkan dengan pengujian dari sisi Admin, berikut adalah Tabel 12 pengujian konfirmasi transaksi pembayaran.

Tabel 12. Pengujian Konfirmasi Pembayaran

\begin{tabular}{lll}
\hline Skenario Uji & $\begin{array}{l}\text { Hasil yang } \\
\text { diharapkan }\end{array}$ & $\begin{array}{l}\text { Hasil } \\
\text { Pengujian }\end{array}$ \\
\hline Memasukkan & Menampilkan & Berhasil $\checkmark$ \\
username dan & $\begin{array}{l}\text { Pesan } \\
\text { password }\end{array}$ & "Username / \\
Tidak Benar & $\begin{array}{l}\text { Password } \\
\text { Wrong" }\end{array}$ & \\
\hline Memasukkan & Menampilkan & Berhasil $\checkmark$
\end{tabular}

email dan Halaman

password Dashboard

dengan Benar

Menekan Icon Menekan Berhasil $\checkmark$

Edit Pada Halaman

Daftar Nomor Detail Invoice

Invoice

\begin{tabular}{lll}
\hline Memasukkan & Status & Berhasil $\checkmark$ \\
Nilai Benar & Pembayaran & \\
pada & menjadi & \\
Konfirmasi & "Sudah & \\
Pembayan & Dikonfinasi"
\end{tabular}

Pembayaran Dikonfirmasi"

Memasukkan Status $\quad$ Berhasil $\checkmark$

Nilai Salah Pembayaran

pada menjadi

Konfirmasi "Bukti

Pembayaran Transfer

\begin{tabular}{lll} 
& Salah" & \\
\hline Menekan Icon & Menghapus & Berhasil $\checkmark$ \\
Delete Pada & Invoice &
\end{tabular}

Delete Pada Invoice

Daftar Nomor Tersebut

Invoice

Menekan Icon Menampilkan Berhasil $\checkmark$

Edit Produk Halaman Edit Produk

\begin{tabular}{|c|c|c|}
\hline $\begin{array}{l}\text { Mengisi } \\
\text { Kriteria } \\
\text { Produk yang } \\
\text { ingin diedit } \\
\text { Tidak Benar }\end{array}$ & $\begin{array}{l}\text { Menampilkan } \\
\text { Pesan "There } \\
\text { is an error" }\end{array}$ & Berhasil $\checkmark$ \\
\hline $\begin{array}{l}\text { Mengisi } \\
\text { Kriteria } \\
\text { Produk yang } \\
\text { ingin diedit } \\
\text { dengan Benar }\end{array}$ & $\begin{array}{l}\text { Kriteria } \\
\text { Produk } \\
\text { Berubah }\end{array}$ & Berhasil $\checkmark$ \\
\hline $\begin{array}{l}\text { Menekan } \\
\text { Tombol } \\
\text { Tambah } \\
\text { Produk } \\
\end{array}$ & $\begin{array}{l}\text { Menampilkan } \\
\text { Halaman } \\
\text { Tambah } \\
\text { Produk }\end{array}$ & Berhasil $\checkmark$ \\
\hline $\begin{array}{l}\text { Mengisi } \\
\text { Kriteria } \\
\text { Produk yang } \\
\text { ingin } \\
\text { ditambahkan } \\
\text { dengan Benar }\end{array}$ & $\begin{array}{l}\text { Menambahkan } \\
\text { Produk Baru }\end{array}$ & Berhasil $\checkmark$ \\
\hline $\begin{array}{l}\text { Mengisi } \\
\text { Kriteria } \\
\text { Produk yang } \\
\text { ingin } \\
\text { ditambahkan } \\
\text { Tidak Benar }\end{array}$ & $\begin{array}{l}\text { Menampilkan } \\
\text { Pesan "There } \\
\text { is an error" }\end{array}$ & Berhasil $\checkmark$ \\
\hline
\end{tabular}
Berdasarkan hasil pengujian konfirmasi 
transaksi pembayaran produk pada Tabel 12 diatas, menunjukkan bahwa seluruh fungsi yang diperlukan dalam melakukan konfirmasi pembayaran yang dilakukan oleh website admin Asy-Syifa CARE berjalan sesuai dengan hasil yang diharapkan.

\section{KESIMPULAN}

Hasil kesimpulan yang penulis sampaikan dari hasil dan pembahasan ini adalah sebagai berikut:

1. Digital marketing lebih berpotensi dari marketing tradisional karena banyak costumer yang mencari produk obat-obatan herbal melalui media online khususnya media website. Hal ini disebabkan pada sifat digital marketing yang lebih engaging.

2. Desain atau tampilan website yang menarik, berpengaruh terhadap suksesnya sebuah brand dalam pangsa pasar. Apabila sebuah brand memiliki produk yang baik namun desainnya yang kurang mendukung, maka daya beli dan kepercayaan dari costumer akan berkurang.

3. Fitur atau pelayanan yang mudah dalam melakukan transaksi jualbeli menjadi daya tarik bagi costumer. Umumnya, costumer akan beralih ke kompetitor sejenis jika pelayanan yang diberikan cukup rumit.

4. Desain yang baik, tidak cukup untuk mencerminkan image dari sebuah startup. Selain desain, dibutuhkan konten yang informatif serta promosi yang kreatif agar dapat menarik minat dari costumer.

\section{REFERENSI}

Anggraini, D. (2017). Pertumbuhan Penduduk terhadap Kualitas Penduduk. Retrieved from https://www.kompasiana.com/dessyals/5a2e86 99ab12ae0230409f93/pertumbuhan-pendudukterhadap-kualitas-penduduk

Assidqi, M., Prasetyo, Y. A., \& Adi, T. N. (2015). Pembangunan Aplikasi Web E-commerce Kelompok Tani Katata Dengan Metode Itterative And Incremental. EProceedings of Engineering, 2(2) https://doi.org/10.1080/23273798.2018.15068 86

BPS. (2014). Persentase Penduduk yang Mempunyai Keluhan Kesehatan dan Mengobati Sendiri menurut Provinsi, Daerah Tempat Tinggal, dan Jenis Kelamin, 2009-2014. Retrieved from https://www.bps.go.id/dynamictable/2018/03/2 0/1287/persentase-penduduk-yangmempunyai-keluhan-kesehatan-danmengobati-sendiri-menurut-provinsi-daerahtempat-tinggal-dan-jenis-kelamin-20092014.html
BPS. (2015). Jumlah Penduduk dan Laju Pertumbuhan Penduduk Menurut Kabupaten/Kota di Provinsi DKI Jakarta 2015. Retrieved from https://jakarta.bps.go.id/statictable/2017/01/30/ 136/jumlah-penduduk-dan-laju-pertumbuhanpenduduk-menurut-kabupaten-kota-diprovinsi-dki-jakarta-2010-2014-dan-2015.html

Destiningrum, M., \& Adrian, Q. J. (2017). SISTEM INFORMASI PENJADWALAN DOKTER BERBASSIS WEB DENGAN MENGGUNAKAN FRAMEWORK CODEIGNITER ( STUDI KASUS : RUMAH SAKIT YUKUM MEDICAL CENTRE ). Jurnal TEKNOINFO, 11(2), 30-37.

Hendini, A. (2016). Pemodelan UML Sistem Informasi Monitoring Penjualan dan Stok Barang (Stuidi Kasus: Distri Zhezha Pontianak). Jurnal Khatulistiwa Informatika, IV(2), 107-116. https://doi.org/10.2135/cropsci1983.0011183X 002300020002x

Heriyanto, B. D., Kurniawan, I. A., \& Taufik, I. (2017). Sistem Aplikasi Perpustakaan Berbasis Web Menggunakan Framework Codeigniter pada SMAS Islamic Centre Web Based Library Application System Using Code Igniter Framework at SMAS Islamic Center. Jurnal Ilmiah SISFOTENIKAJu, 7(2), 187196.

Isa, I. G. T., \& Hartawan, G. P. (2017). Perancangan Aplikasi Koperasi Simpan Pinjam Berbasis Web (Studi. Jurnal Ilmiah Ilmu Ekonomi, 5(10), 139-151.

Prabowo, D. (2015). Website E-Commerce Menggunakan Model View Controller ( Mvc) Dengan Framework Codeigniter. Jurnal Ilmiah DASI, 16(1), 23-29. https://doi.org/1411-3201

Suandi, A., Khasanah, F. N., \& Retnoningsih, E. (2017). Pengujian Sistem Informasi Ecommerce Usaha Gudang Cokelat Menggunakan Uji Alpha dan Beta. INFORMATION SYSTEM FOR EDUCATORS AND PROFESSIONALS, 2(21), 61-70. Retrieved from https://media.neliti.com/media/publications/23 4474-pengujian-sistem-informasi-ecommerce-us-2bea597f.pdf

Supardi, S., \& Susyanty, A. L. (2010). The Use of Traditional Medicine in Self Medication in Indonesia (Data Analysis of Susenas 2007). Buletin Penelitian Kesehatan, 38(2), 80-89. Retrieved

from http://bpk.litbang.depkes.go.id/index.php/BPK /article/view/100/174 